\title{
Advanced Manufacturing under Impact / Shock Loading: Principles and Industrial Sustainable Applications
}

\author{
Academician Prof. Dr.-Ing. Dr.h.c. Prof.h.c. Athanasios G. Mamalis \\ Project Center for Nanotechnology and Advanced Engineering (PC-NAE), \\ NCSR "Demokritos", Athens, Greece \\ a.mamalis@inn.demokritos.gr
}

Keywords: Advanced Manufacturing, Advanced Materials, Net-Shape Manufacturing, Biomedical Engineering, Transport, Energy, Environment, Defense, Safety, Industrial Sustainability

\begin{abstract}
Trends and developments in advanced manufacturing of advanced materials from macro- to nanoscale subjected to static, lowspeed / high speed / hypervelocity impact and shock loading, with sustainable industrial applications to net-shape manufacturing, bioengineering, transport, energy and environment, defense and safety, an outcome of the very extensive, over 50 years, work on these scientific and industrial areas performed by the author and his research international team, are briefly outlined. The impact of such advanced materials, manufacturing and loading techniques, products and applications on many technological areas, e.g. the manufacturing/machine tool sector, communications / data storage, transportations, health treatment, energy conservation, environmental and human-life protection, is significant and highly beneficial.
\end{abstract}

\section{Introduction}

The topics considered, an outcome of the very extensive academic and industrial work over 50 years on these fields performed by the author and his research international team, may be listed as:

- Mechanics (Structural plasticity, Low / High speed impact loading, Hypervelocity impact, Shockwaves loading)

- Precision / Ultraprecision manufacturing from macro-, micro- to nanoscale (Metal forming, Metal removal processing, Surface engineering / Wear, Non-conventional techniques)

- Nanotechnology / Nanomaterials manufacturing

- Ferrous and non-ferrous materials (Metals, Ceramics, Superhard, Polymers, Composites, Multifunctional), from macro- to nanoscale (Nanostructured materials, Nanoparticles, Nanocomposites)

- Powder production and processing technologies (High strain-rate phenomena and treatment under shock: Explosives, Electromagnetics, High temperature / high pressure techniques)

- Biomechanics / Biomedical engineering

- Transport / Crashworthiness of Vehicles: Passive and active safety for passengers and cargo (Surface transport: Automotive, Railway; Aeronautics: Aircraft, Helicopters)

- Energy (Superconductors, Semiconductors, Electromagnetics, Solar cells, Photovoltaics, Nuclear reactors)

- Environmental aspects (Impact on climate change: Nanotechnology; Automotive industry; Aeronautics industry)

- Safety (Detection of explosives and hazardous materials)

- Defense (Ballistics, Projectiles hitting targets, Shock loading) 
- Industrial sustainability

Some trends and developments in Advanced Manufacturing from macro- to nanoscale in the important engineering topics from industrial, research and academic point of view: nanotechnology, precision /ultraprecision engineering and advanced materials (metals, ceramics, polymeric, composites/nanocomposites) under static, low/high speed impact, hypervelocity impactand shock loading, with sustainable industrial applications to net-shape manufacturing, bioengineering, transport, energy/environment and defense / safety, are briefly outlined in the present ESHP 2019 Invited Lecture.

\section{Manufacturing Technology Principles}

The principles of advanced manufacturing technology may be identified by six main elements, see Fig. 1, with the central one being the enforced deformation to the material, i.e. the processing itself, brought about under consideration of the interface between tool and workpiece, introducing interdisciplinary features for lubrication and friction, tool materials properties and the surface integrity of the component. The as-received material structure is seriously altered through the deformation processing, subjected from static to very high-strain rate phenomena / shock loading, therefore, materials testing and quality control before and after processing are predominantly areas of interest to the mechanics, manufacturing and materials scientists. The performance of the machine tools together with the tool design are also very important, whilst, nowadays, the techno-economical aspects, like the notion of manufacturing systems, e.g. automation, modeling and simulation, rapid prototyping, process planning, computer integrated manufacturing, energy conservation and recycling, as well as environmental aspects are important in advanced manufacturing engineering [1].

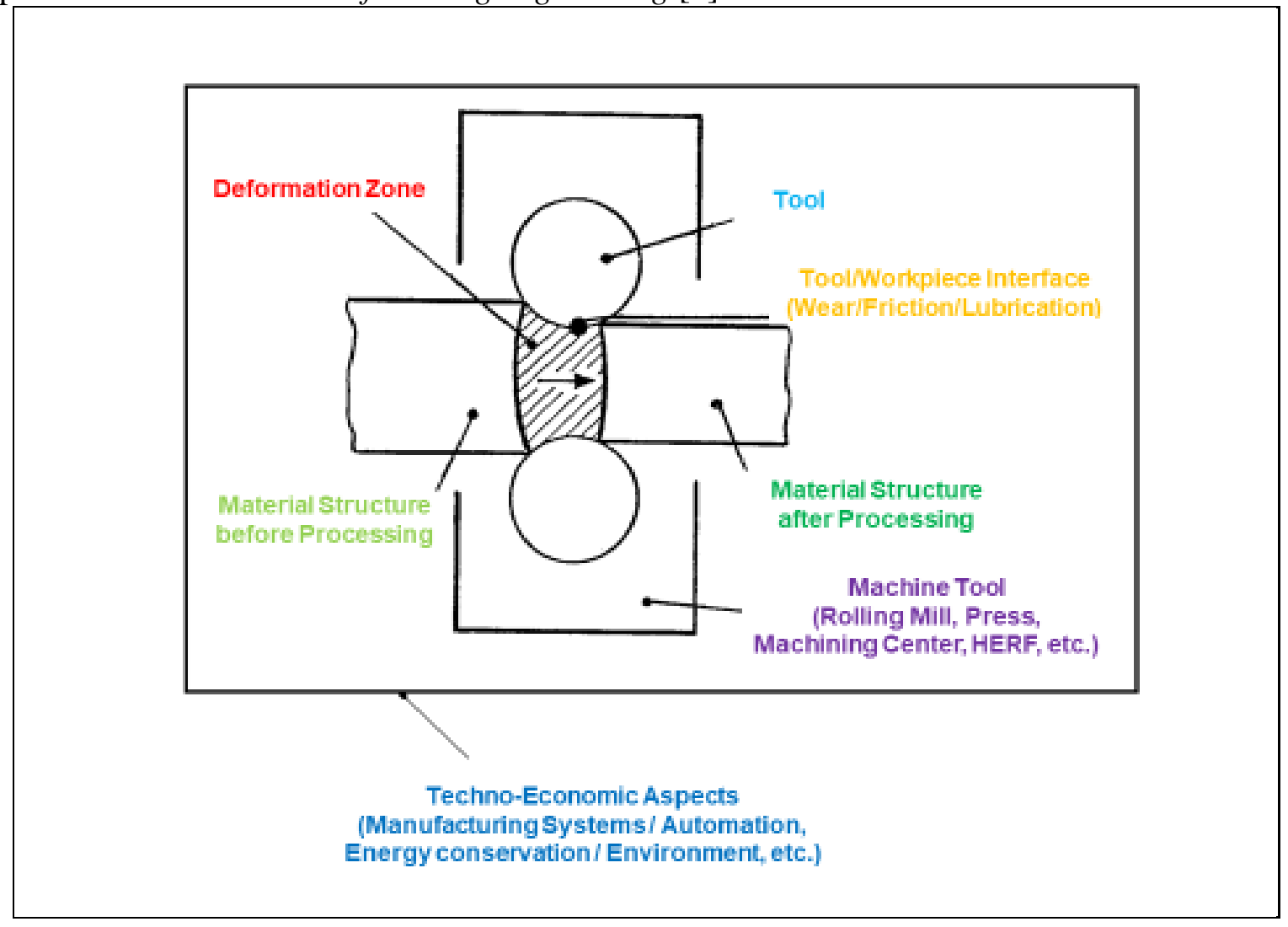

Fig. 1 Advanced manufacturing technology principle 
The structural plasticity mechanics, governing the deformation of the material, see Fig. 2, are mainly associated with $[1,2]$ :

(a) Low strain-rate phenomena, i.e. deformation under static-, low speed impact loading, for metals, polymers and composite materials, see Fig. 2(i).

In this case, the material behavior is characterized by its stress-strain curve. Ductile metals and polymers are plastically deformed with the formation of stationary and traveling plastic hinges.

Contrary to this ductile mechanism, the deformation mechanism for brittle composite materials is achieved by material fragmentation developing extensive microcracking processes easily controlled and depended on the properties of fibers and resins the fibers orientation.
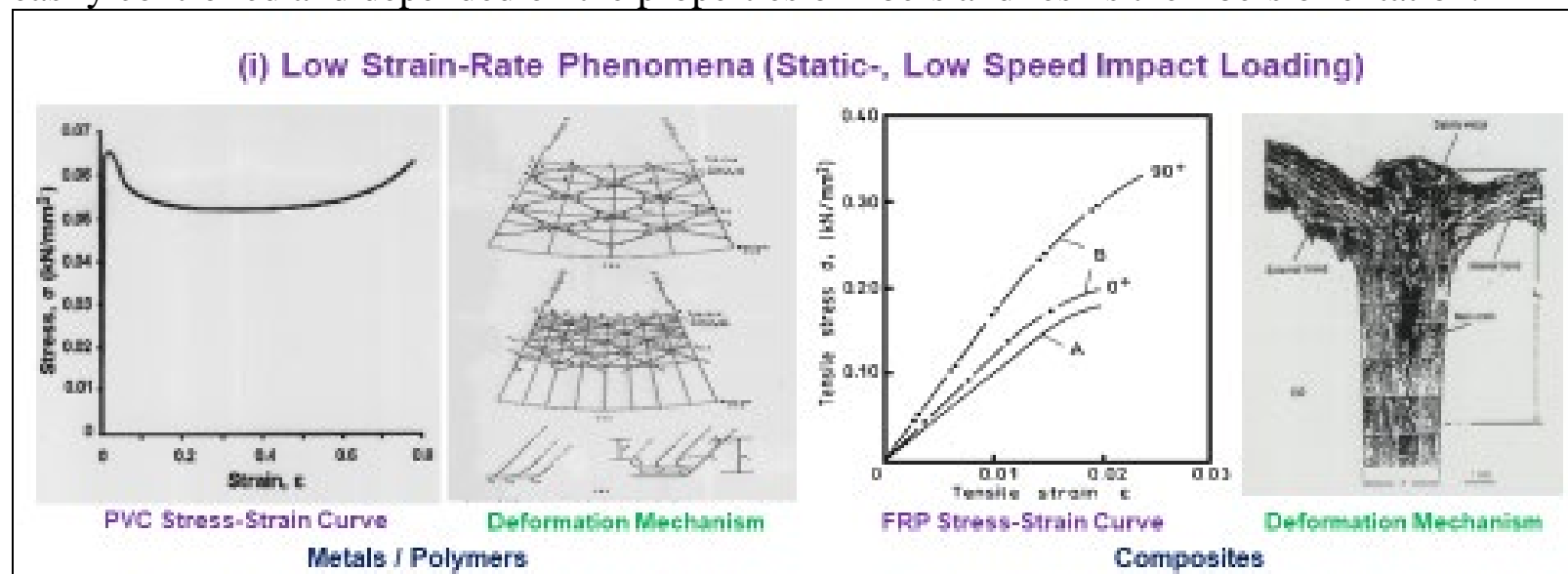

(ii) High Strain-Rate Phenomena (High Speed/ Hypervelocity Impact-, Shockwaves Loading)
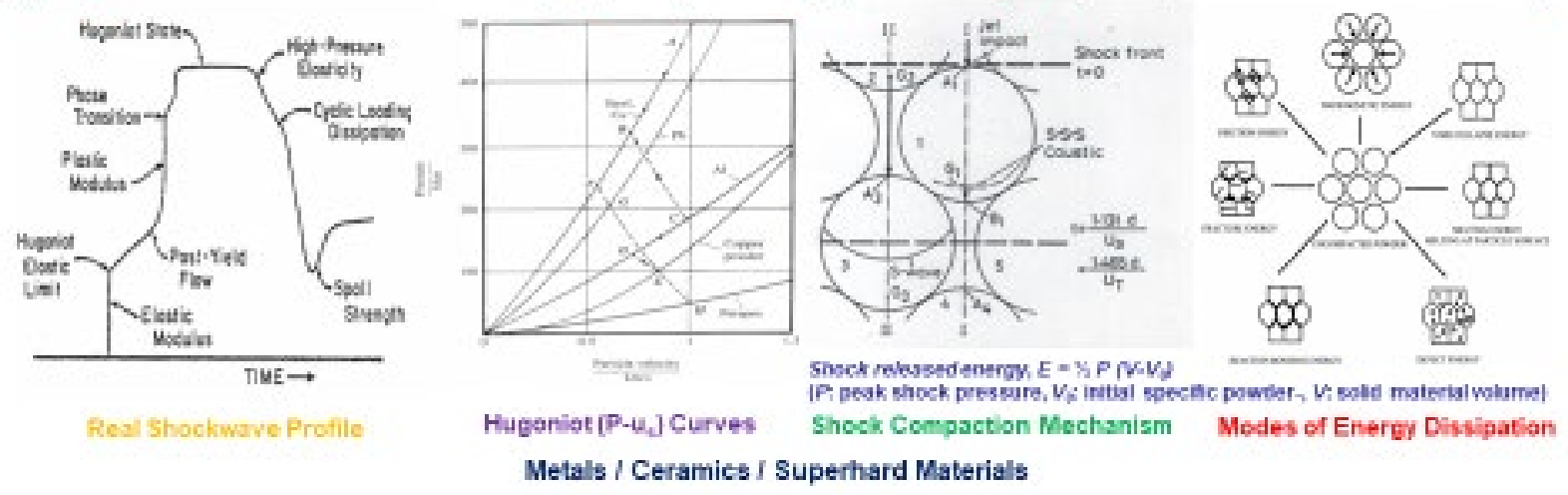

Fig. 2Structural plasticity mechanics

(b) High strain-rate phenomena, i.e. deformation under high speed / hypervelocity impact-, shockwaves loading), for metals, ceramics and superhard materials (diamonds, CBN), see Fig. 2(ii).

During dynamic / shock loading, a longitudinal, P-shockwave, with a real shockwave profile (pressure, $P$ vs time, $t$ ), is initiated, traveling into the body at high speed, calculated from the corresponding state of the material under shock conditions, i.e. its Hugoniot curve (pressure, $P$ specific volume, $V$ relationship), defined as the loci of all shock states and essentially describing the material properties. The particles are accelerated into the pores at high velocities, impacting each other, which results in the development of shear $S$-waves in the particles due to jet impact at a point on the particle surface, traveling inside the particle and reflected at its surface resulting in jet formation due to spalling, with subsequent loading of the already formed jet moving between the interparticle voids in the same direction as the shock. The frictional energy release results, 
therefore, in melting at the surface regions with the associated bonding once the material is solidified. In the consolidation of brittle materials, particle fracture also occurs, leading to the filling of the gaps, whilst reactive elements can also be added to help the bonding process. The high-pressure state creates numerous lattice defects and dislocation substructures leading very often to localise shearing and microcracking. The energy dissipation modes due to shockwaves and the relevant mechanisms, are related to the shock released energy, $E=1 / 2 P\left(V-V_{0}\right)$, where $P$ is the peak shock pressure, $V_{0}$ the initial specific powder volume and $V$ the volume of the solid material.

Quality of manufactured parts is mainly determined by their dimensional and shape accuracy, the surface integrity, and the functional properties of the products. Development of manufacture engineering is related to the tendency to miniaturization and is accompanied by the continuous increasing of the accuracy of the manufactured parts. The two main trends towards the miniaturization of products are, see Fig. 3:

- Precision/ Ultraprecision manufacturing (Metal forming, Metal removal processing, Surface engineering / Wear, Non-conventional techniques), see Fig. 3(i), carried out by machine tools with very high accuracy;

- Nanotechnology processing, see Fig. 3(i), i.e. the fabrication of devices with atomic and / or molecular scale precision by employing new advanced energy beam processes that allow for atom manipulation and therefore, the design and manufacture of the nanostructured materials, having every atom or molecule in a designated location and exhibiting novel and significantly improved physical, chemical, mechanical and electrical properties.

The various stages of nanomaterials manufacturing are listed in Figure 3(ii) [3].

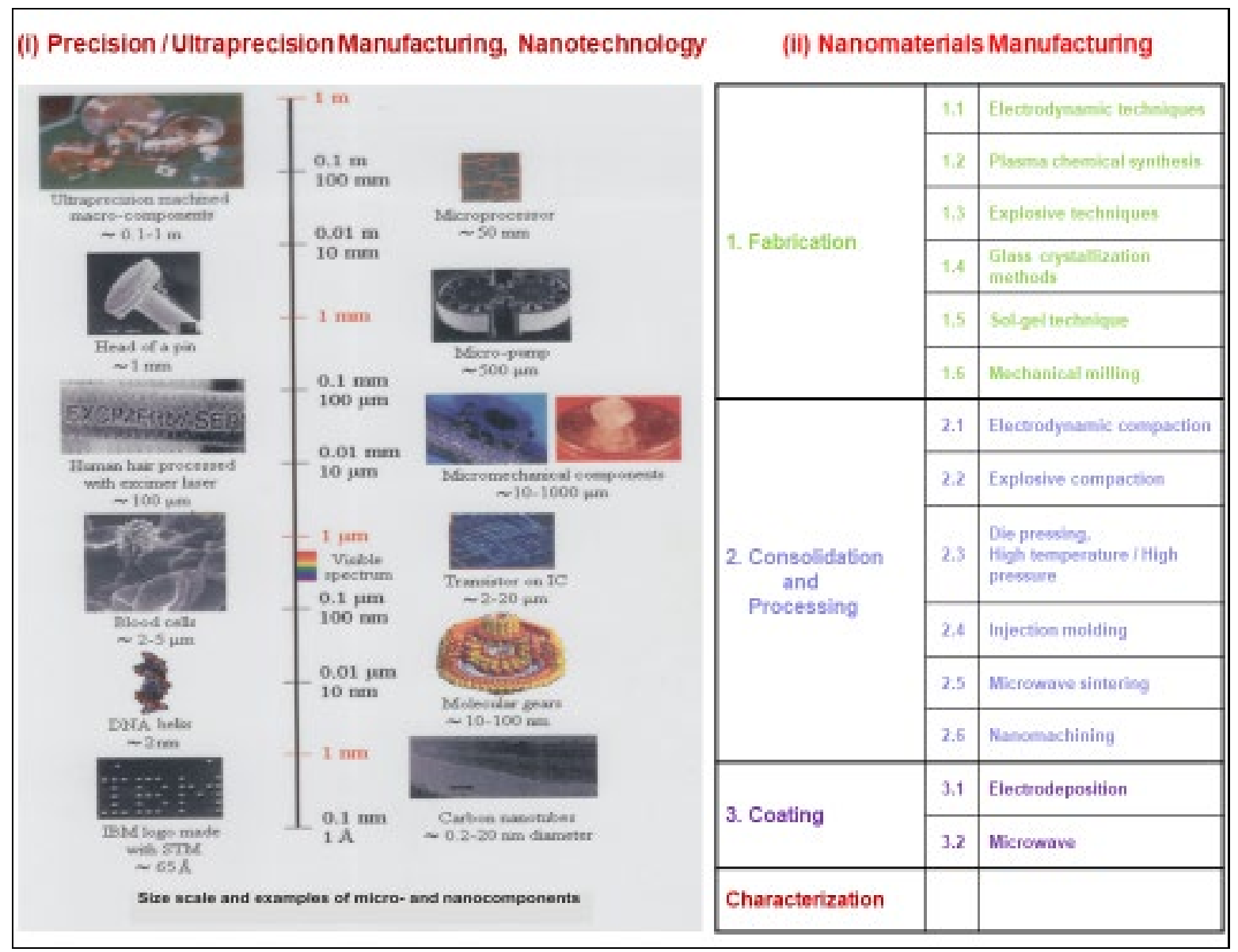

Fig. 3 
Macro-, micro- and nanoproducts under shock loading involve the production of ultrafine materials (metals, ceramics, mixtures) by explosive and/or electromagnetic compaction as well as high temperature /high pressure die pressing techniques, see Fig. 4 [4]. These materials can be utilized as a basic material or as the modifying additives at the manufacturing of sintered powdery ceramics, hard-alloy and ceramic composites, nanoparticles reinforced metal and polymeric, matrix composites, abrasive pastes and suspensions and polishing ones, chemical catalysts and sorbents.

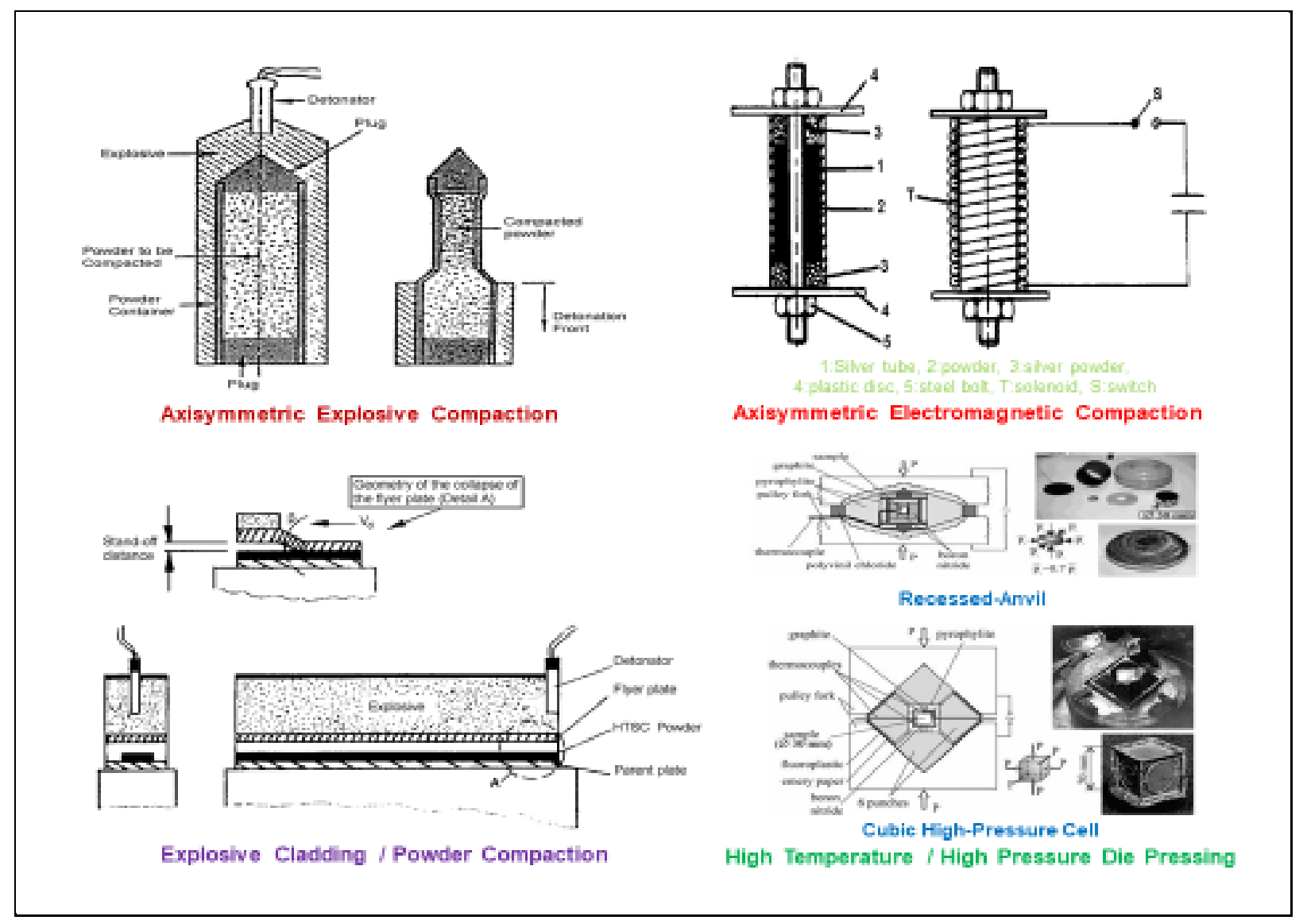

Fig. 4 Net-shape manufacturing under shock loading

\section{Industrial Sustainable Applications}

Sustainability nowadays is challenged on many fronts, among the most prominent ones, the advanced manufacturing may be considered. Industrial sustainable applications in advanced manufacturing from macro- to nanoscale of advanced materials (metals, ceramics, superhard materials, polymers, composites / nanocomposites) under static, low- / high-speed / hypervelocity impact and shock loading, an outcome of the very extensive, over 50 years, academic and industrial work on these fields of the author in association with his vast research international team worldwide, are briefly listed below.

(a) Powder production and processing technologies

(High strain-rate phenomena and treatment under shock: Explosives, Electromagnetics, High temperature / high pressure techniques).

Crushing of brittle materials grains can be achieved by shock loading. These high-strain rate phenomena are used for producing materials of micro- and nanoscale grains. By applying 
properly calculated and directed shock waves created by explosion, $\mathrm{Al}_{2} \mathrm{O}_{3}, \mathrm{MgO}, \mathrm{ZrO}_{2}, \mathrm{Mo}, \mathrm{Ti}$, metal $\mathrm{MgB}_{2}$ and ceramic high-Tc superconductors are treated for reducing their grain size into nanoscale.

Compaction of such materials by shockwaves has the advantage that during the compaction phase grain growth does not occur. The high-speed shockwaves with high energy content can be created either by initiating high explosives (explosive compaction) or by discharging electric capacitors (electromagnetic compaction). In successfully consolidated products, interparticle regions that are molten and rapidly solidified are usually observed, which is more profound in metals than in ceramics. The main defect of compacted ceramics is the presence of cracks, propagating through the whole component, that can be eliminated by novel compaction designs, powder preheating or even by using reactive mixtures to produce heat by exothermic reaction, triggered by the shock wave passage. During compaction, the powder surfaces are accelerated into the pores at high velocities, impacting each other, with frictional energy release, leading to melting at the surface regions with the associated bonding once this material is solidified. In consolidated brittle materials, particle fracture also occurs, leading to the filling of the gaps, whilst reactive elements can also be added to help bonding process. The high-pressure state creates numerous lattice defects and dislocation substructures leading very often to localise shearing and microcracking.

(i) Consolidation mechanism stages and particle shape changes after time: (a) $t=0$ (beginning of impact); (b) $t=1.465 d / U_{T}$; (c) $t=2 \cdot 1.465 d / U_{T}+t_{c}$, see Fig. 5(i).

(ii) Experimental validation of the shock compaction mechanism by explosive compaction of spherical copper powders, see Fig. 5(ii).

Shock released energy, $E=1 / 2 P\left(V-V_{0}\right) \quad\left(P\right.$ : peak shock pressure; $V_{0}$ : initial specific powder volume; $V$ : volume of solid material).

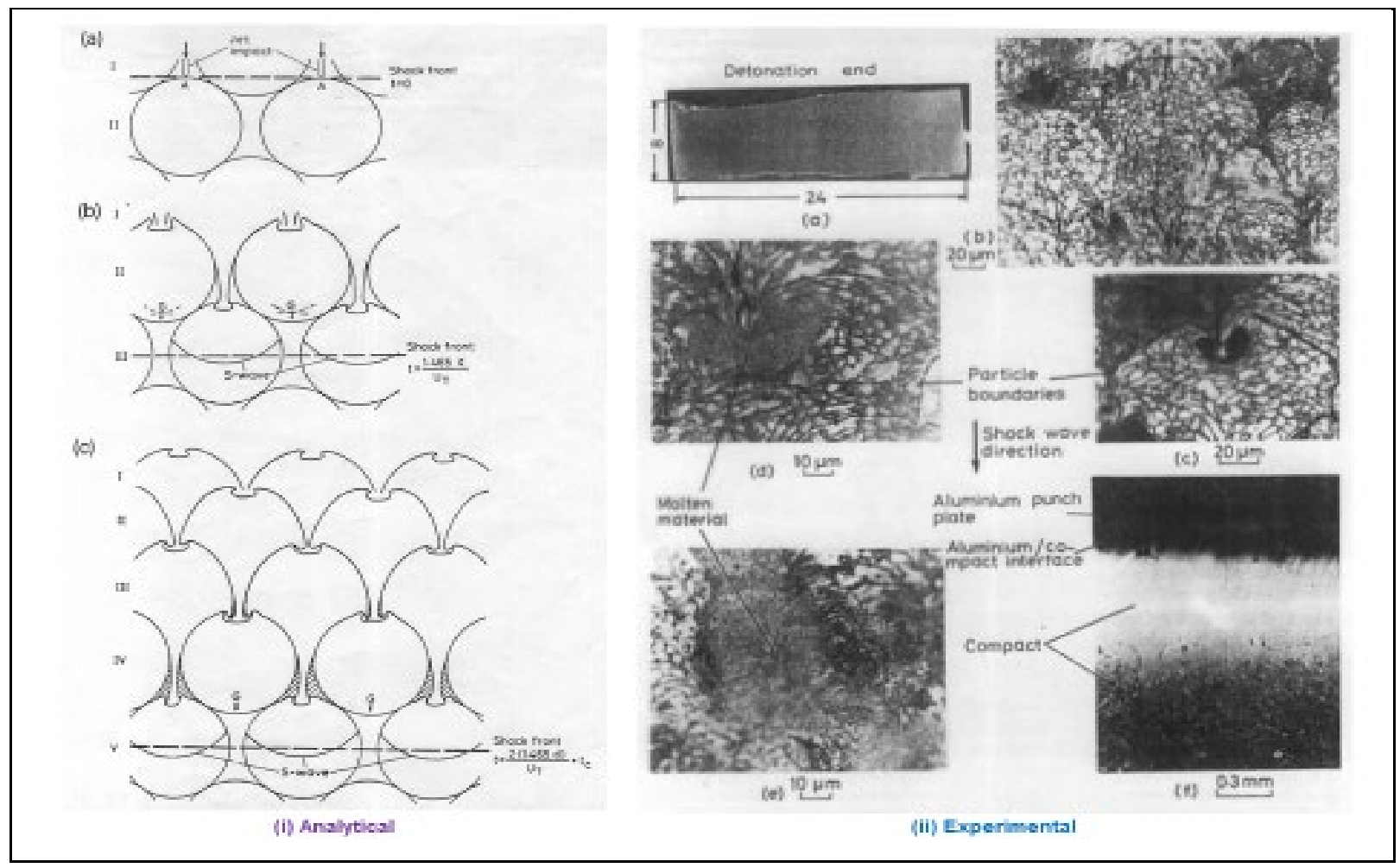

Fig. 5 Consolidation mechanism 


\section{(b) Biomechanics / Biomedical engineering}

Two industrial sustainable cases are considered, see Fig. 6:

(i) Shock production of nanodiamonds doped with boron is obtained by detonating highexplosives, at detonation velocities up to $7 \mathrm{~km} / \mathrm{s}$, in an explosive chamber. Industrial applications of these nanodiamonds are related toultraprecision nanoprocessing / nanolithography, with nanodiamonds used as multifunctional Scanning Tunneling Microscope Berkovich pyramidshaped tips, and to biomedical engineering, with diamond nanoplatforms employed for targeted delivery of diagnostic and therapeutic agents in oncology, see Fig. 6(i) [5].

(ii) Sapphire head / sapphire cup / titanium stem hip-joint endoprostheses, produced by ultraprecision manufacturing, constitute an important biomechanics sustainable application in biomedical orthopedics and are associated with the active safety for the passengers protection during crash, see Fig. 6(ii) [6].

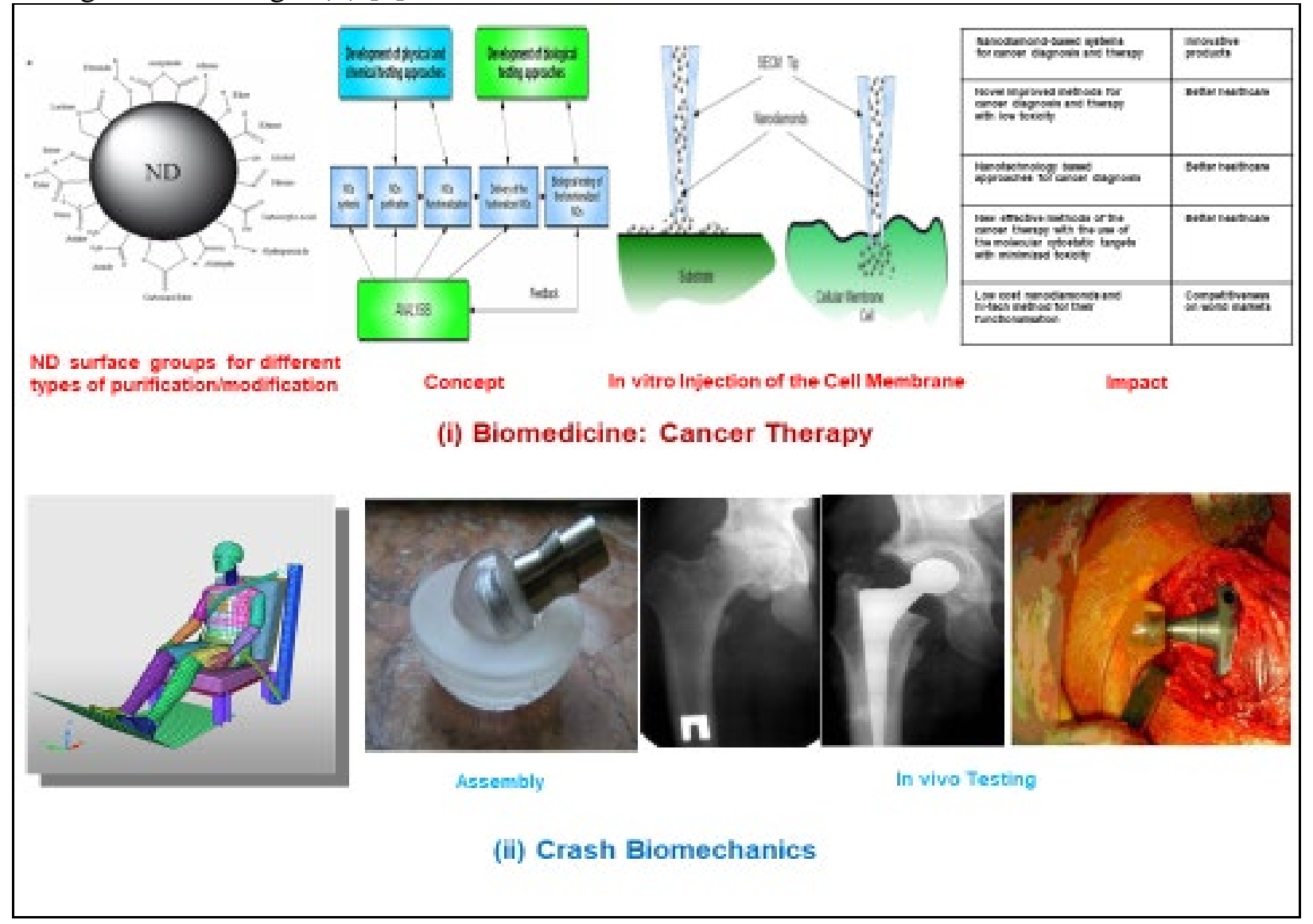

Fig. 6 Biomechanics/Biomedical engineering

(c) Energy

Topics considered are: Super- and Semiconductors, Electromagnetics, Solar Cells / Photovoltaics and Nuclear Reactors. In particular, materials that present zero resistance at a certain critical temperature, $\mathrm{T}_{\mathrm{c}}$ above the absolute zero are named Superconductors and the related phenomenon Superconductivity. High-temperature superconducting materials of the YBCO and BSCCO ceramic compounds $\left(\mathrm{T}_{\mathrm{c}}=77-93 \mathrm{~K}\right)$, fabricated by various physicochemical techniques (solid state reaction, sol-gel, etc.) in the form of powders / nanoparticles, and Lowtemperature superconducting nanostructured $\mathrm{MgB}_{2}$ metallic materials $\left(\mathrm{T}_{\mathrm{c}}=49 \mathrm{~K}\right)$, whilst highenergy rate powder compaction processes, e.g. explosive and electromagnetic compaction and high pressure / high temperature techniques, and subsequent forming and metal removal 
processing, are used to manufacture superconductive ceramics and metals with unique properties, with applications to electricity and transport, see Fig. 7(i) [7].

(d) Environmental aspects: Impact on climate change

Nanotechnology as well as the automotive and the aeronautics industries are among the factors that have a profound impact on energy consumption and hence greenhouse gas emissions (GHG).

- Aeronautics Industry Impact on Climate Change: A novel design of $5^{\text {th }}$ generation gas turbine

engines for transport and energy, using structural ceramics blades manufactured by selfpropagating high-temperature synthesis and electrochemical dimensional processing, is proposed, reducing the effect of thermo-mechanical and dynamic loading.

- The technological impact of nanotechnology on climate change as well various strategies to Combat it, see Fig. 7(ii), by following the energy supply chain, i.e. renewable energies; photovoltaics and solar energy, wind energy, fuel cells and hydrogen economy; energystorage, batteries, supercapacitors; thermoelectric conversion efficiency in combustion and electric engines; weight reduction by using lighter, stronger and stiffer nanocomposite materials with the potential to significantly reduce dead weight and promote energy efficiency in transportation, and, furthermore, by utilising nanotechnology applications involving nanomanufacturing, use of bulk and surface nanomaterials and nanomaterials of biological origin or interacting with living organisms, may be helpful inside a reduction global climate change mitigation effort [8].

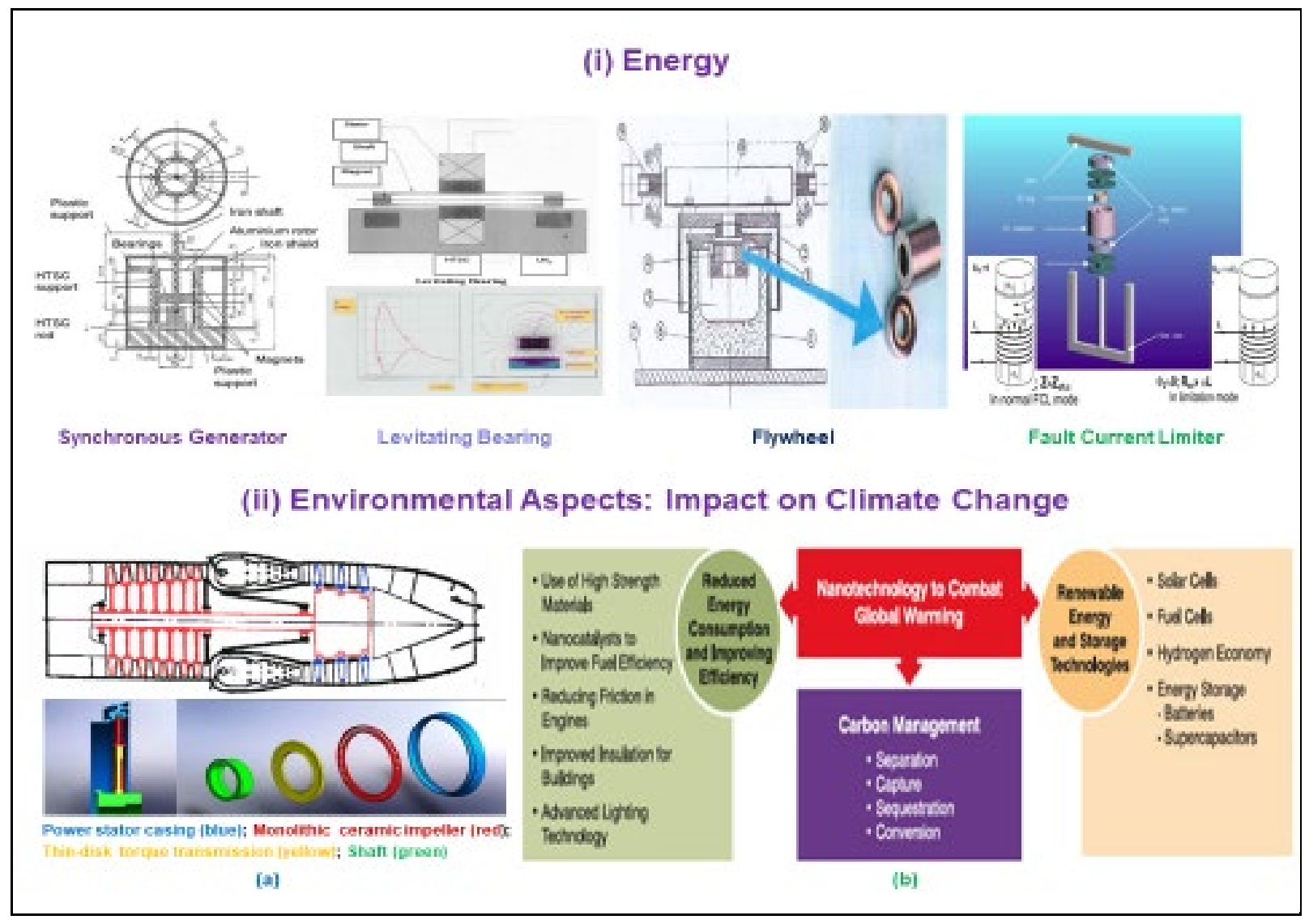

Fig. 7

(e) Transport / Crashworthiness of Vehicles: Passive and active safety for passengers / cargo 
Crashworthiness studies provide with the mechanism by which a proportion of impact energy is absorbed by the collapsing structure, whilst a small amount is transferred to the passenger in order to improve the crash resistance of the vehicle. To obtain effective crashworthy behavior, associated with the passive safety, a Crashworthiness study must be carried out in the very early design stages, considering analytical and numerical modeling and experimental in situ and at laboratory scale of thin-wall structural components subjected to various loading conditions, in particular, low and high speed impact. Note, also, that, activesafety is associated with the passengers and cargoprotection during crash. For passengers, it is mainly related to biomedical engineering, with the hip-joint endoprostheses being an important crash biomechanics application, see Fig. 6(ii). My, over 40 years, extensive scientific and industrial work on the crash mechanism of metals, polymers, composite materials and advanced hybrid composite structures, related to surface transport, automotive and railway, and aeronautics (aircraft, helicopters), is briefly outlined in Figs. 8(i), 8(ii) and 8(iii), respectively [9].

The relation between $\mathrm{CO}_{2}$ emissions from road vehicles, trains, ships and aircrafts, attributed to each sector of the human activity, and the climate change is established, Electric and hybrid cars considerably reduce emissions resulting in both global warming and air pollution locally, and, in addition, to help curb the world's dependence on oil. Sustainable technologies to reduce or totally eliminate the impact of vehicles on climate change are: Hybrid Electric Vehicles (HEV), Plug-in Hybrid Electric Vehicles (PHEV), Battery Electric Vehicle with Range Extender (REBEV), Battery Electric Vehicles (BEV) and Fuel Cell Electric Vehicles (FCEV), seeFig. 8(i).

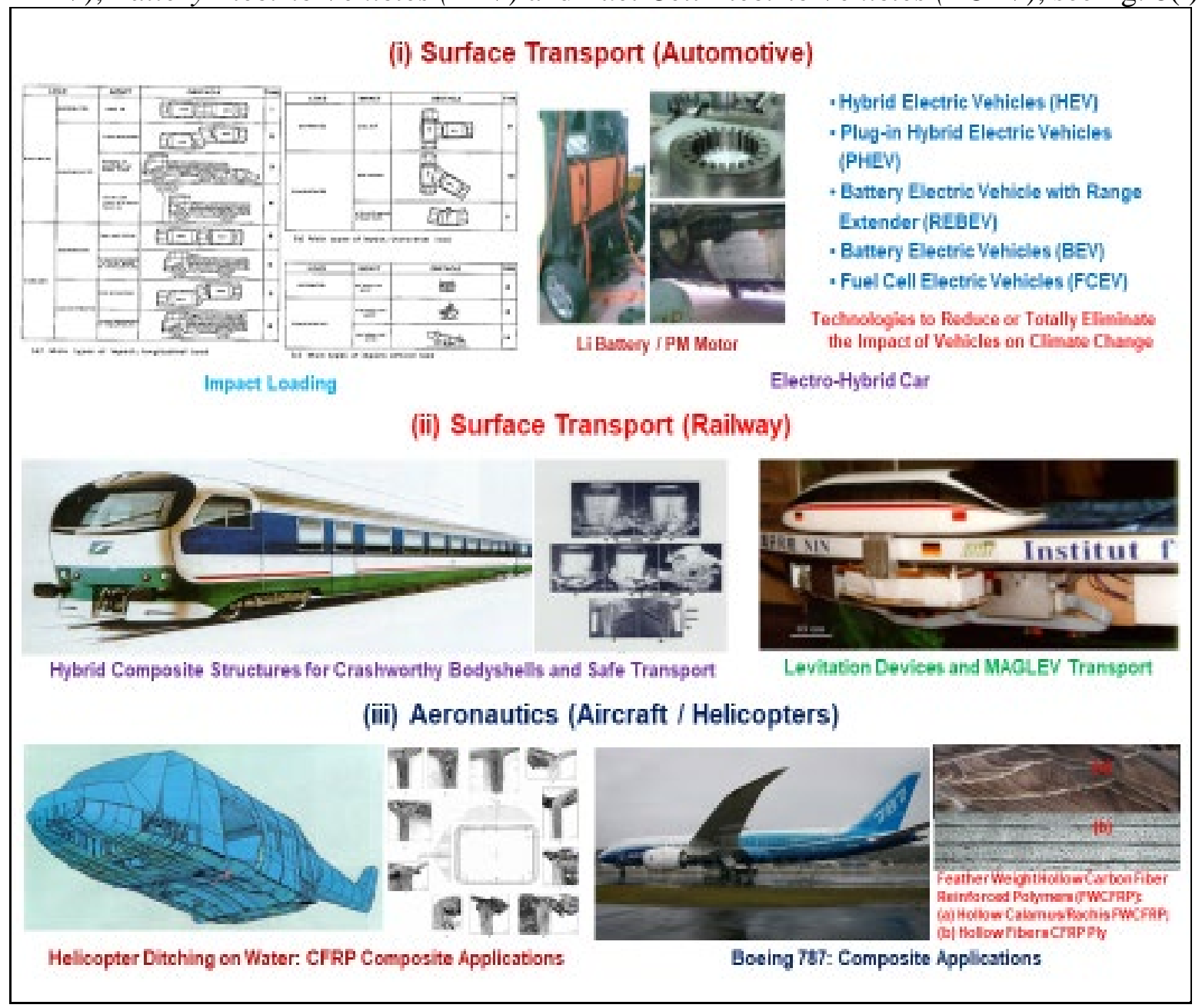

Fig. 8 


\section{(f) Defense}

High strain-rate phenomena related to hypervelocity impact loading are employed in the case of ballistics and projectiles / bullets hitting targets for the proper design and manufacture of the armory in Military installations, e.g. tanks, weapons etc., see Fig. 9(i) [2].

(g) Safety

Prevention of terrorist attacks is of utmost importance, with explosives being the chosen weapons targeting any populated area. Three processes are necessary for the detection of explosives and hazardous materials in the air: collectivity, consisting of front-end collection and pre-concentration; separation and detection, providing selectivity and sensitivity of the threat, respectively. It results to the manufacture of a multi-channel explosive detection sensor with different sets of sorbents that provide separation of various groups of explosives, consisting of carbon nanotubes in combination with various monomers-organic compounds effectively interacting with certain nitro-aromatics and using a diamond plate as substrate for the measuring matrix due to the chemical inertness and stable physical-mechanical characteristics of the diamond.

Development of new methods against improvised explosive devices (IEDs) and home-made explosives (HMEs) and improvement of existing facilities for faster, more sensitive and cheaper explosive detection and neutralization of person- or vehicle-borne IEDs, are the objectives of the Integrated Network for the Detection of Explosives(INDEX) concept, see Fig. (ii) [10].

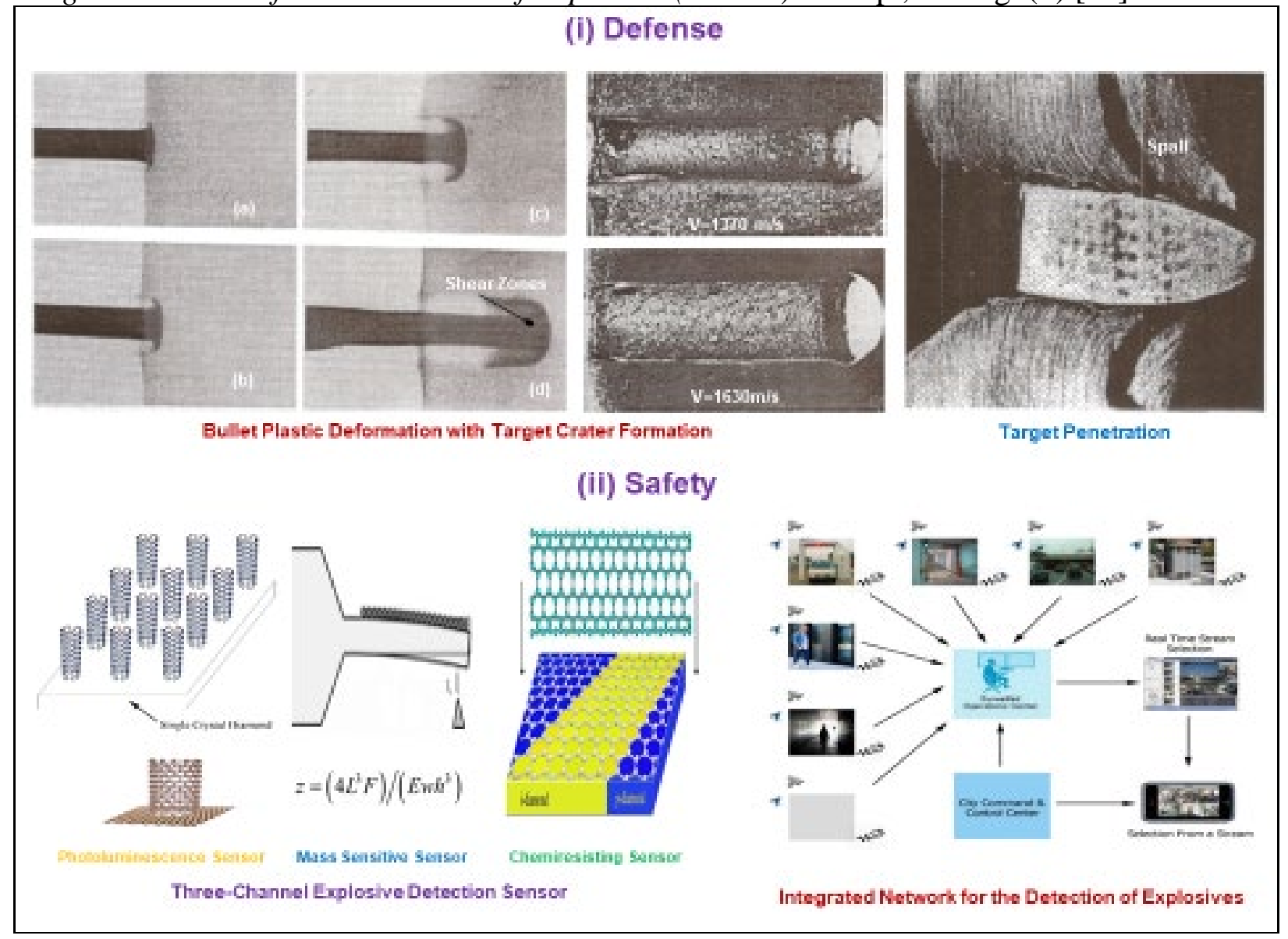

Fig. 9 


\section{Concluding Remarks}

The benefits of such advanced materials, manufacturing and loading techniques, products and industrial sustainable applications in many technological areas are significant. The impact of these technologies in every day's life is considered to be great, since it will make the manufacturing / machine tool sector, communications, transportations, data storage, health treatment, energy conservation, environmental and human-life protection and many other technological applications better, faster, safer, cleaner and cheaper.

At this point, it is necessary to clearly identify the value of a reasonably sound knowledge of the kind presented so far:

Industry is conducted both for profit-making and at the same time for supplying goods to the mass of the people at minimum, economic prices; primary concern is the manufacturing cost.

Defence industries or requirements are concerned with the product to fulfil a certain task and cost tends to be secondary.

To help carry out these two functions efficiently, Research programs have usually to be put in operation and, in order to do this at minimum cost, the long, costly ladder of research and development must be mounted at as high a level as possible. This is most easily done by enhancing international research cooperation between Research Centers, Universities and Industry. In that respect, the PC-NAE, continuing the over 40 years established international cooperation worldwide of my Laboratory of Manufacturing Technology of the NTUA, is encouraging it by expanding all these cooperation activities with the establishment of Multinational Clusters, like the rather newly established Shockwaves Cluster. Quoting the Great Ancient Greek Philosopher Aristotle:

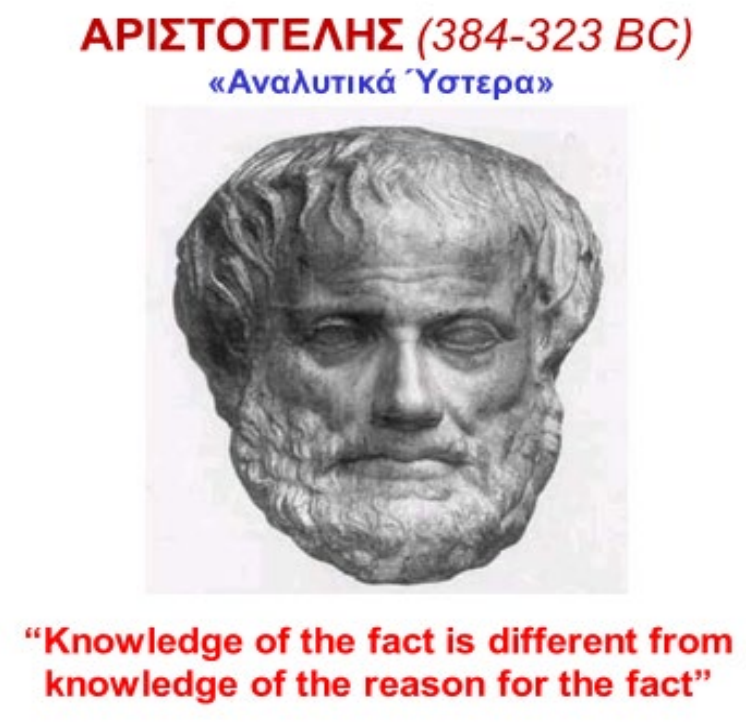

\section{References}

[1] Johnson, W., Mamalis A.G., Engineering Plasticity: Theory of Metal FormingProcesses, Springer Verlag (CISM Courses and Lectures No 139), Wien, 1977, pp. 345

[2] Johnson W, MamalisA.G., Gegenüberstellung statischer und dynamischer Schadens oder Deformationserscheinungen, Fortschritt-Berichte der VDI-Zeitschriften, Reihe 5, Nr.32, Düsseldorf, 1977, pp. 78

[3] Mamalis A.G., Recent advances in nanotechnology, Journal of Materials Processing, Technology, 2007. 181: pp52-58 
[4] Mamalis A.G., Powder processing. International Journal of Production Engineering and Computers, 2003. 5(6): pp 15-31

[5] Lysenko O.G., Grushko V.I., Dub S.N., Mitshevich E.I., Novikov N.V., MamalisA.G., Manufacturing and characterization of nanostructures using Scanning Tunneling Microscopy with diamond tip. Journal of Nano Research, 2016. 42: pp. 14-46, https://doi.org/10.4028/www.scientific.net/jnanor.42.14

[6] Mamalis A.G., Lytvynov K.A., Filipenko V.A., Lavrynenko S.N., Ramsden J.J., Soukakos P.N., Perfection of contemporary hip-joint endoprostheses by using a sapphire-sapphire friction pair. Journal of Biological Physics and Chemistry, 2007. 7: pp. 3-5. https://doi.org/10.4024/10701.jbpc.07.01

[7] Mamalis A.G., Szalay A., Manolakos D.E., Pantazopoulos G., Processing of High Temperature Superconductors at High Strain Rates,Technomic Publishing Co,USA. 2000, pp. 276, https://doi.org/10.1201/9781420014266

[8] Mamalis A.G., Ramsden J.J., Holt G.C., Vortselas A.K., Mamali A.A., The effect of nanotechnology in mitigation and adaptation strategies in response to climate change. Nanotechnology Perceptions, 2011. 7: pp. 159-179, https://doi.org/10.4024/n08ma11a.ntp.07.03

[9] Mamalis A.G., Manolakos D.E., Demosthenous G.A. and Ioannidis M.B., Crashworthiness of Composite Thin-Walled Structural Components, Technomic Publishing Co, USA, 1998, pp. 269

[10] Lysenko O.G., Grushko V.I., Mitshevich E.I. and Mamalis A.G., Three channel trace explosive detector using diamond. (to be published) 